\title{
Larvicidal efficacy of temephos impregnated onto kenaf cellulose nanofibre to control Aedes aegypti (Diptera: Culicidae) larvae
}

\author{
Pengiran, H. ${ }^{1,2}$, Kamaldin, J. ${ }^{1 *}$, Leo, B.F. ${ }^{3,4}$, Ahmad, H. ${ }^{5}$ \\ ${ }^{1}$ Advanced Medical and Dental Institute, Universiti Sains Malaysia, Bertam 13200, Kepala Batas, Pulau Pinang, Malaysia \\ ${ }^{2}$ Faculty of Civil Engineering Technology, Universiti Malaysia Perlis, 02600 Arau, Perlis, Malaysia \\ ${ }^{3}$ Faculty of Medicine, Universiti Malaya, 50603 Kuala Lumpur, Malaysia \\ ${ }^{4}$ Nanotechnology and Catalysis Research Centre (NANOCAT), Universiti Malaya, 50603 Kuala Lumpur, Malaysia \\ ${ }^{5}$ Vector Control Research Unit (VCRU), School of Biological Sciences, Universiti Sains Malaysia, 11800 Gelugor, Pulau Pinang, Malaysia \\ *Corresponding author: jahangirkamaldin@gmail.com
}

\section{ARTICLE HISTORY}

Received: 18 May 2021

Revised: 16 August 2021

Accepted: 16 August 2021

Published: 30 September 2021

\begin{abstract}
Larviciding is an effective control method in managing mosquito-borne diseases. However, most of the current larvicide formulations have raised environmental concerns due to the presence of non-biodegradable inert or carrier materials. Therefore, the utilisation of biodegradable natural cellulosic fibres has created much attention. This study aims to evaluate the application of biodegradable kenaf cellulose nanofibre (KCNF) in larvicide formulation where the larvicide, namely temephos, is impregnated onto the fibre matrix $(\mathrm{KCNF}+\mathrm{T})$. The bioefficacy of the formulation was evaluated against Aedes aegypti (A. aegypti) mosquito larvae. The presence of the temephos on the KCNF was evaluated through micromorphological analysis using a field emission scanning electron microscope (FESEM) and a transmission electron microscope (TEM), while the quantity of temephos impregnated, released, and retained on the fibres upon dispersion in water were determined using high performance liquid chromatography (HPLC). It was observed that $97 \%$ of the temephos $(0.1 \mathrm{mg})$ were impregnated on the KCNF. Upon dispersion in water, $53 \%$ of the temephos were released from the KCNF+T and the retention of temephos on the KCNF+T gradually decreased to $30 \%, 17 \%$, and $7 \%$ on the first, third, and fifth month, respectively. Exposure of the A. aegypti larvae to the KCNF+T at concentrations ranging between 0.006 to $0.01 \mathrm{mg} / \mathrm{L}$ was effective in killing $A$. aegypti larvae at $17-25$ folds as compared to using the temephos without KCNF. Microscopic examination revealed the accumulation of the KCNF on the larval appendages. In conclusion, this study demonstrated that the utilisation of KCNF in pesticide formulation is an effective way of delivering the temephos to control A. aegypti mosquito larvae.
\end{abstract}

Keywords: Cellulose nanofibre; temephos; larvicide; nanocarrier; dengue.

\section{INTRODUCTION}

Mosquitoes are one of the common vectors that can spread different kinds of viruses and parasites such as dengue, malaria, Zika virus, and Chikungunya (WHO, 2020). Dengue fever is among the important communicable diseases transmitted by the Aedes aegypti (A. aegypti) mosquito. To date, dengue fever has become a global burden with an estimation of 390 million infections per year, and the number of cases has been increasing tremendously (WHO, 2020). Many factors, such as urbanisation, increase of human travel, climate change, human behaviour, and conditions of the local environment, for example the presence of artificial water containers which offer good larval breeding sites have been identified as possible root causes for the rapid spread of the dengue virus worldwide (Jansen \& Beebe, 2010).
One of the elements in integrated mosquito control programmes is the suppression of the $A$. aegypti mosquito population during the larval stage by larviciding at the breeding habitat before it turns into adult mosquitoes (WHO, 2004; US EPA, 2019). Killing mosquitoes at the breeding site is considered as the main reduction source as they are concentrated, immobile, and accessible during the larval stage, thus killing them at this stage significantly impacts the overall mosquito population. Moreover, through a targeted approach, insecticide applications on mosquito larvae are more reliable, cost-effective, and reduce the spread of pesticides to non-target organisms (WHO, 2004; Floore, 2006; US EPA, 2019).

A commercial larvicide product is formulated with a mixture of an active ingredient (e.g. insecticide) and inert ingredients (e.g. surfactant, emulsion, and sand granules), 
which are utilised to enhance the effectiveness of the insecticide against mosquito larvae (WHO, 2004; Floore, 2006; US EPA, 2019). One of the common larvicide active ingredients is temephos $\left(0,0, O^{\prime}, O^{\prime}\right.$-tetramethyl $0,0^{\prime}$-thiodi-p-phenylene bis(phosphorothioate). This organophosphate pesticide has been used globally against $A$. aegypti for the prevention and control of dengue transmission (WHO, 2006). It has low acute toxicity and low water solubility of $0.04 \mathrm{mg} / \mathrm{L}$ at $25^{\circ} \mathrm{C}$ (WHO, 2011). Since mosquito larvae mainly live underneath the water surface, the use of a carrier material in the larvicide formulation is essential for pesticides that have low solubility in water as this method improves the release of the active ingredients into the environment (Yusoff et al., 2016). Current carrier materials used in larvicide formulation include mineral sand, synthetic polymer, and polyethylene pellets - however, the use of these materials have raised environmental concerns due to their non-biodegradable origins and the pollution they cause (Yusoff et al., 2016). For example, larvicides impregnated on polyethylene (PE) pellets and used to control the release of larvicides are non-biodegradable and lead to environmental pollution. The material contains persistent organic pollutants such as polychlorinated biphenyl (PCB), polycyclic aromatic hydrocarbons (PAHs), and dichlorodiphenyltrichloroethane (DDT) (Kase \& Branton, 1986; Rios et al., 2007).

As the world moves towards sustainable development through the promotion of good health and well-being as adopted by the United Nations in 2015, larvicide formulations should therefore also be environmental-friendly by fulfilling the criteria of being biodegradable, renewable, and with low toxicity to non-target organisms (UN, 2015; Schorkopf et al., 2016). Nanocellulose is one of the biodegradable natural polymers that can be used to form environment-friendly larvicide formulations (Ong et al., 2017). It is a polysaccharide consisting of a repeating unit of glucose and a primary constituent of the plant cell wall, which can be processed further into cellulose nanocrystal and cellulose nanofibre (French, 2017; Tuerxun et al., 2019). Cellulose nanofibre (CNF) is made of plant pulp such as kenaf that goes through mechanical treatment (e.g. high-pressure homogeniser) to be produced at dimensions of 1-100 nm (Nechyporchuk et al., 2016). Kenaf (Hibiscus cannabinus) is a fibre plant consisting of an inner core fibre and an outer bast fibre (Abdul Khalil et al., 2010). Kenaf-based CNF (KCNF) has remarkable physical and chemical properties such as being biodegradable, has high loading capability, has high aspect ratio, is hydrophilic, and has low crystalline value - thus, the CNF can be considered as a viable alternative as a larvicide nanocarrier (Ong et al., 2017).

Nanocellulose has been widely recognised as an environment-friendly carrier in the biomedicine field, but research on the use of nanocellulose as a larvicide carrier is still lacking. To date, only one research was found on the use of modified CNF in the microencapsulation of insect repellent against adult mosquitoes (Kadam et al., 2019). Herein, in the current study, the authors' aim is to assess the application of KCNF in the larvicide formulation where the larvicide, namely temephos, was impregnated onto the KCNF fibres. Subsequently, the bioefficacy of the formulation was evaluated against Aedes aegypti ( $A$. aegypti) mosquito larvae. The KCNF's capability to impregnate, release, and retain temephos upon dispersion into water was analysed using HPLC. Meanwhile, the larvicidal efficacy was evaluated by dispersing the KCNF+T in water containing live A. aegypti larvae, then the larval mortality was observed for 24 to 48 hours. This study highlights the ability and application of KCNF as a biodegradable larvicide nanocarrier with enhanced larvicidal bioefficacy without the use of organic solvents.

\section{MATERIALS AND METHODS}

\section{Materials and chemicals}

In this study, the KCNF suspension $(2.24 \% \mathrm{w} / \mathrm{w})$ was obtained from the Nanotechnology and Catalysis Research Centre, Universiti Malaya (NANOCAT). Details of the KCNF suspension preparation technique have been reported elsewhere (Tuerxun et al., 2019). On the other hand, the technical grade (93\%) temephos was provided by Hextar R\&D International Sdn. Bhd. Malaysia. The chemicals required for the highperformance liquid chromatography (HPLC) analysis were standard temephos 98\%, which was obtained from Dr. Ehrenstorfer ${ }^{T M}$ and analytical grade $n$-hexane and ethyl acetate, which were purchased from EAM Sdn. Bhd. and J.T. Baker, respectively.

\section{Impregnation of temephos to KCNF matrix}

The KCNF suspension was freeze-dried before impregnated with the temephos. Five mg KCNF was impregnated with $0.1 \mathrm{mg}$ of the temephos solution dissolved in acetone. The impregnation process was done through the physical adsorption and solvent evaporation techniques to produce KCNF with temephos (KCNF+T).

\section{Morphology characterization of KCNF+T using FESEM and TEM}

The sample of KCNF+T for morphological characterization using the field emission scanning electron microscope (FESEM) and transmission electron microscopy (TEM) was prepared using the technique described by Pengiran et al. (2021). Surface morphological characterization was evaluated using FEG Quanta 650 FESEM with an accelerating voltage of $30 \mathrm{kV}$ in high vacuum mode, while structural morphology was determined using TEM model Libra 120 Zeiss with an accelerating voltage of $120 \mathrm{kV}$ in bright field mode. Adhesion of temephos on the KCNF+T was confirmed by comparing the TEM image of KCNF without impregnation and temephos compound. The KCNF sample was prepared as described in Pengiran et al. (2021), while the temephos sample was prepared by diluting the $0.1 \mathrm{mg}$ temephos solution into a 1:100 ratio and subsequently followed the sample preparation procedure for TEM. The length and width of the $\mathrm{KCNF}+\mathrm{T}$ particles were counted and measured for at least 200 particles using ImageJ software version 1.51 (Schneider et al., 2012) to get particles size distribution.

\section{Determination of temephos amount impregnated on KCNF, release and retention of temephos using the HPLC}

To determine the amount of temephos impregnated onto the KCNF, $5 \mathrm{mg}$ of KCNF+T was dispersed into a hexane-ethyl acetate (1:1) solvent mixture in $100 \mathrm{~mL}$ volumetric flask and sonicated for 1 minute. Then the mixture was filtered with a $0.45 \mu \mathrm{m}$ nylon syringe filter and the solvent solution was extracted into a $2 \mathrm{ml} \mathrm{HPLC}$ vial for further analysis. The sample was marked as A for further communication. This investigation was carried out freshly, that is within one week after the impregnation of the temephos onto the KCNF.

To investigate the release behavior of the temephos onto the KCNF, $5 \mathrm{mg}$ of $\mathrm{KCNF}+\mathrm{T}$ was dispersed into $100 \mathrm{ml}$ distilled water to achieve the intended amount of temephos equivalent to $1 \mathrm{mg} / \mathrm{L}$ which is the recommended operational dose by the World Health Organization for larvicidal application (WHO, 2006). The suspension was sonicated based on the technique described by OECD (2017) for 45 
minutes at $50 \%$ amplitude setting to remove the nanomaterial aggregation effect due to the freeze-dried prior dispersion. Then the mixture was filtered using a $0.1 \mu \mathrm{m}$ Omnipore PTFE membrane filter (MERCK KGaA, Germany) to remove the KCNF particles. The temephos in the filtrate was extracted using the liquid-liquid extraction technique (Henry et al., 1971). Finally, the sample was put into a $2 \mathrm{ml}$ HPLC vial for further analysis and was marked as B.

The retention of the temephos onto $\mathrm{KCNF}+\mathrm{T}$ carrier was investigated by dispersing $5 \mathrm{mg}$ of $\mathrm{KCNF}+\mathrm{T}$ in water and stored for 1, 3 and 5 months at room temperature. The sample solution was denoted as $C, D$, and $E$ respectively. The solution was filtered using $0.1 \mu \mathrm{m}$ Omnipore PTFE membrane filter (MERCK KGaA, Germany) to collect KCNF+T fibres. Subsequently, the collected $K C N F+T$ residue was extracted with a hexane: ethyl acetate (1:1) solvent mixture in a $100 \mathrm{ml}$ volumetric flask to determine the amount of temephos retained on the $\mathrm{KCNF}+\mathrm{T}$ fibres.

The amount of temephos in all the five samples (A-E) was analysed using the HPLC with a UV-V is detector SPD-20A (Shimadzu Corporation, Japan), column type Zorbax RX-Sil $4.6 \mathrm{~mm} \mathrm{ID} \times 250 \mathrm{~mm}, 5 \mu \mathrm{m}$ (Agilent Technologies, USA) and the HPLC detector was adjusted at $254 \mathrm{~nm}$. The injection volume was $10 \mu \mathrm{l}$ using an automated injector system with a flow rate of $1 \mathrm{ml} / \mathrm{min}$ and an oven temperature of 30 to $85^{\circ} \mathrm{C}$. An isocratic elution system was utilised with a mobile phase of $n$-Hexane and ethyl acetate at a 90:10 ratio. A calibration curve was obtained from concentrations of $0.1 \mathrm{mg} / \mathrm{L}$ to $1.2 \mathrm{mg} / \mathrm{L}$ with $r^{2}=0.999$. The amount of temephos in the samples was quantified based on the sample peak area compared with the standard peak area as shown by the HPLC chromatogram, multiplied with the standard temephos weight over the sample weight as guided by CIPAC (1985).

\section{Larvicidal bioefficacy of KCNF+T against $A$. aegypti larvae}

The bioefficacy of the KNCF+T against $A$. aegypti was evaluated by exposing live larvae to 12 separate test solutions namely distilled water (control), KCNF $(0.5 \mathrm{mg} / \mathrm{L}), \mathrm{KCNF}+\mathrm{T}$, and temephos (TM) solutions based on the procedure described by WHO (2005). In accordance with the WHO test procedures, mosquito larvae of the late third and early fourth instar were exposed for 24 to 48 hours to the test solution at several concentrations, and the resultant mortality was recorded (WHO, 2005).

The KCNF+T and TM test solutions were prepared in distilled water at five temephos concentrations ranging from 0.002 to $0.01 \mathrm{mg} / \mathrm{L}$. The $A$. aegypti larvae of late third to early fourth instar were obtained from the Vector Control Research Unit (VCRU) of Universiti Sains Malaysia (USM). The larvae were pre-conditioned in a holding cup at laboratory condition with a temperature of $21 \pm 2{ }^{\circ} \mathrm{C}$ and a 12 -hour day/night photoperiod with feed provided regularly. After the preconditioning period, 25 healthy larvae were transferred using a strainer into treatment cups with a total of 20 cups for each test solution. The bioefficacy of the solutions against the mosquito larvae was measured based on the number of dead and moribund larvae observed at the 24 and 48 hours upon exposure to the test solutions. The larvae were considered dead when found to be motionless or nonresponsive when touched, and moribund when incapable of rising to the water surface, or not showing diving characteristics (WHO, 2005). The percentage of larval mortality was calculated as the total number of larvae dead divided by the total of 25 larvae that were exposed to the test solutions following procedures by WHO (2005). The larvae's surface morphology was examined under a stereo microscope model Olympus SZX10 with stereo control Olympus DP20.

\section{Data analysis}

The particle size distribution in terms of width \& length of the $\mathrm{KCNF}+\mathrm{T}$ was expressed as mean \pm standard deviation (SD), while the larval mortality percentage was converted into percentage mortality (\%) as calculated using Microsoft Excel (version 16). The larvicidal bioefficacy result was accepted for log dosage-Probit analysis if the control larvae mortality was less than $5 \%$. If the control larvae mortality shown was $5 \%-20 \%$, the result was corrected based on Abbot's formula as below (WHO, 2005).

$$
\text { Mortality }(\%)=\frac{X-Y}{X} \times 100
$$

where; $X=$ percentage mortality in the test solution and $Y=$ percentage mortality in the control solution.

If the control larvae pupate was more than $10 \%$, the bioefficacy result was rejected and the experiment was repeated (WHO, 2005). Subsequently, the log dosage-Probit mortality regression analysis was performed to estimate the $50 \%$ lethal concentration $\left(\mathrm{LC}_{50}\right)$ when the percentage larvae mortality in the test solutions fell between 10\% - 95\% (Finney, 1971). A Kruskal-Wallis ANOVA test was carried out to determine the mean difference between KCNF+T and TM efficacy with a significance level of $p<0.05$ using IBM SPSS Statistics version 27 software (IBM Corp, 2020). The normal distribution of the larval mortality percentage was assessed using the Shapiro-Wilks test and Levene's test for homogeneity of variances with a significance level set at $p>0.05$. A Dunn's post hoc analysis with Bonferroni adjustments was conducted to determine if the pairs of the test concentrations' mean differed significantly (Laerd Statistics, 2017).

\section{RESULTS AND DISCUSSION}

\section{Micromorphology of KCNF+T using FESEM and TEM}

The FESEM and TEM images of the surface and structural morphology of KCNF+T are shown in Figures $1(a)$ and $1(b)$, respectively, while TEM images of KCNF and temephos are shown in Figure 2(a) and 2(b). The FESEM micrograph in Figure $1(a)$ shows the $K C N F+T$ with a rough surface and deposition of solid matter (red circles) among the network structure of the fibres, evidencing the impregnation of the temephos and consistent with findings by Badawy et al. (2015). The authors had reported a rough surface morphology after the incorporation of temephos on the chitosan/alginate capsule used. Figure 1 (b) shows the presence of grey matter clusters representing the temephos impregnated on the $\mathrm{KCNF}+\mathrm{T}$ as compared with the TEM image of KCNF without temephos impregnation (Figure 2a). The $\mathrm{KCNF}+\mathrm{T}$ particles were found to be in nanoscale at $150 \pm 7.68 \mathrm{~nm}$ and $8.90 \pm$ $0.32 \mathrm{~nm}$ length and width, respectively, and existed as a high aspect ratio nanomaterial with a length to diameter (L/D) ratio of 16.9 (Rasmussen et al., 2018). The KCNF+T aggregation shown in the TEM image could be due to the freeze-dried and swelling effects during the temephos impregnation process. Despite the aggregation and swelling effects, the $\mathrm{KCNF}+\mathrm{T}$ fibres were still within the nanoscale range (Bhandari et al., 2017; De France et al., 2017; Pötzinger et al., 2017). 


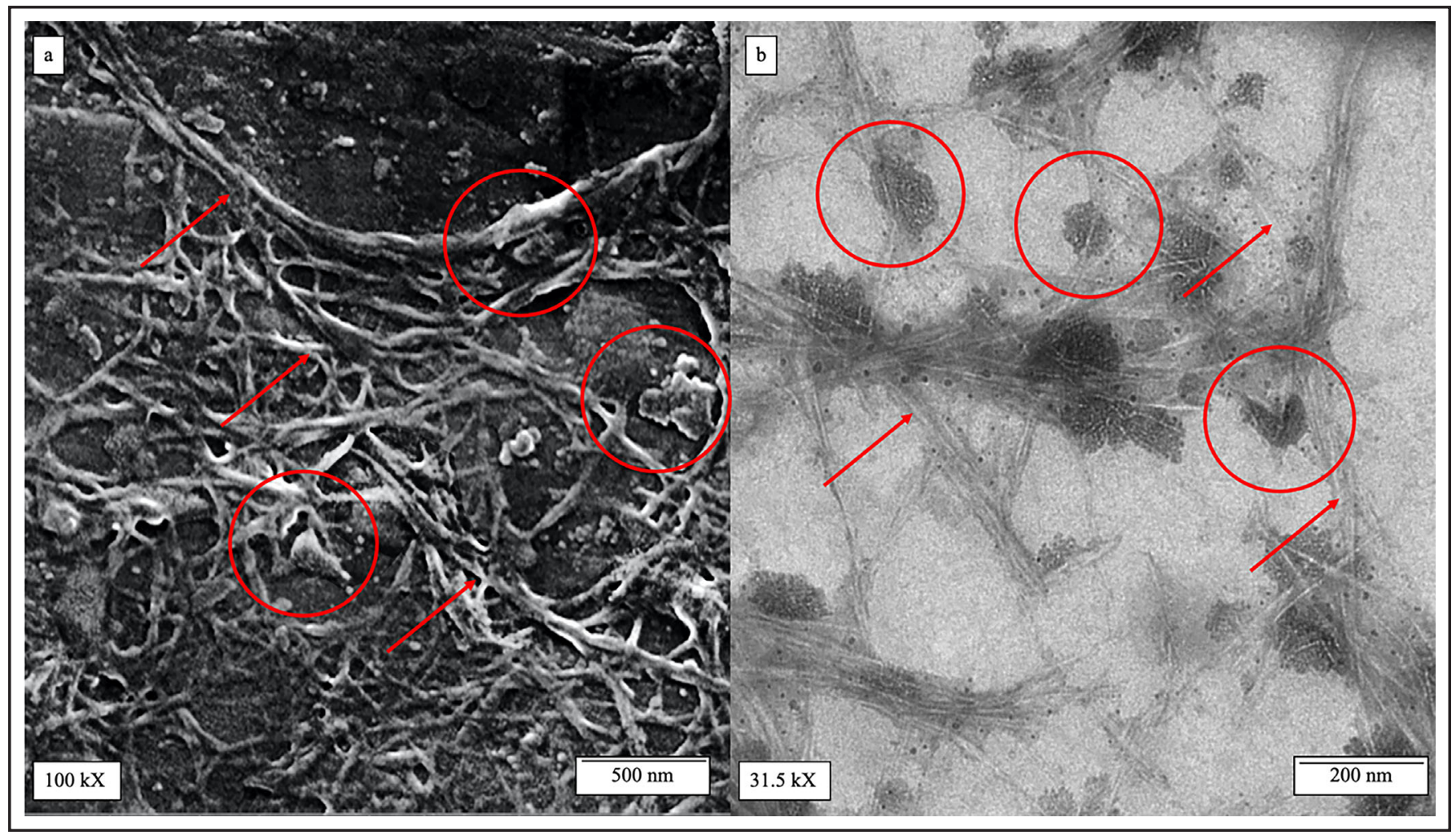

Figure 1. Electron micrographs of kenaf cellulose nanofibre impregnated with temephos (KCNF+T); FESEM micrograph of KCNF+T at 100.0kX (a) and TEM micrograph at 31.5kX (b). Example of the temephos impregnation was indicated by the red circles with the fibres identified with red arrows.
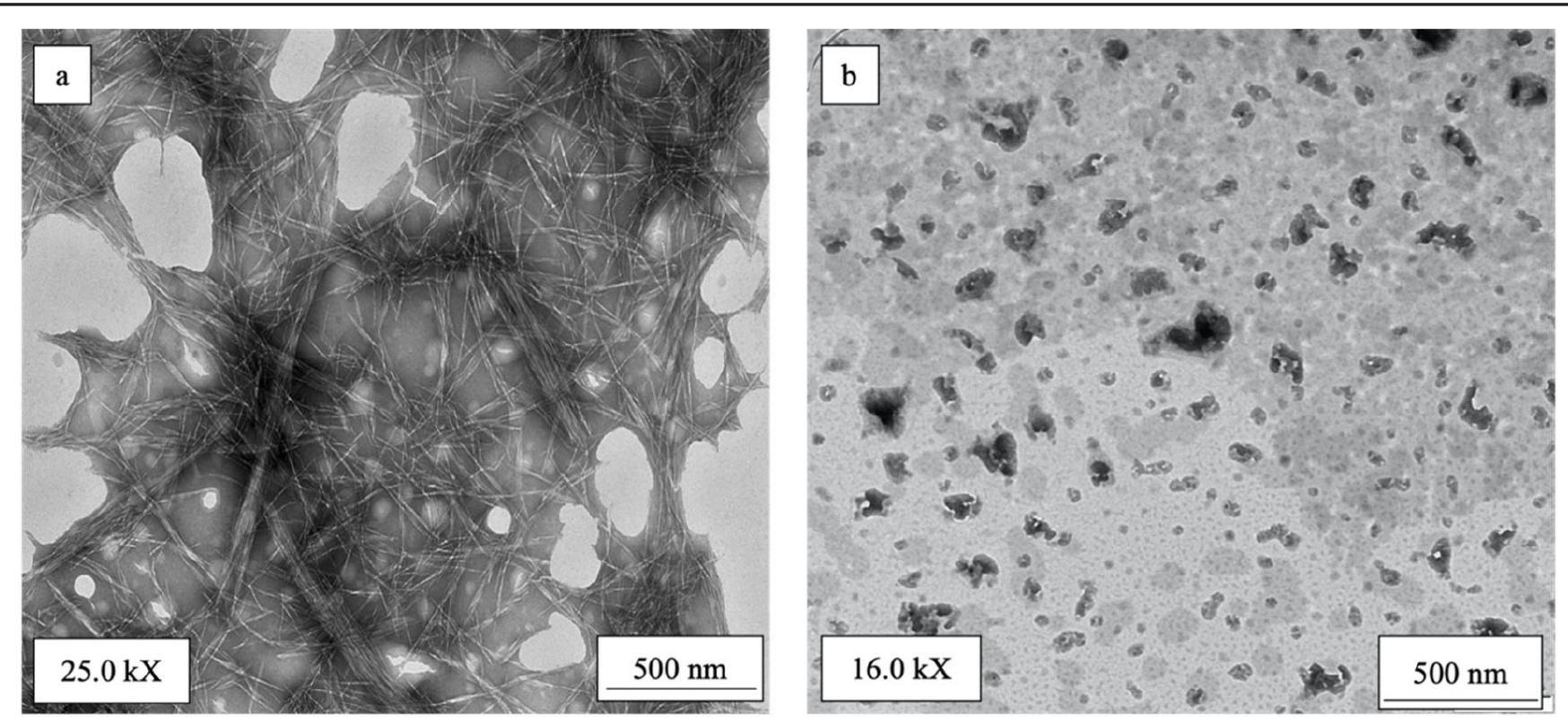

Figure 2. TEM micrographs of kenaf cellulose nanofibre (KCNF) at $25.0 \mathrm{kX}$ (Pengiran et al., 2021) (a) and temephos at $16.0 \mathrm{kX}$ (b).

Determination of temephos amount impregnated on KCNF+T, release, and retention of temephos using the HPLC

The HPLC results of the temephos amount in samples $A, B, C$, $D$, and $E$ are presented in Table 1. The HPLC result of sample A showed that $0.097 \mathrm{mg}$ temephos was impregnated on $5 \mathrm{mg}$ $\mathrm{KCNF}+\mathrm{T}$, resulting in $97 \%$ of the temephos successfully impregnated onto the $\mathrm{KCNF}+\mathrm{T}$. The impregnation process produced a KCNF+T with $1.94 \% \mathrm{w} / \mathrm{w}$ temephos. Sample B indicated $0.051 \mathrm{mg}(52.3 \%)$ of temephos released from the $\mathrm{KCNF}+\mathrm{T}$ after dispersed in water. As for samples $\mathrm{C}, \mathrm{D}$, and $\mathrm{E}$, the $K C N F+T$ retained $30 \%, 16 \%$, and $7 \%$ of the temephos for 1 , 3 , and 5 months, respectively, upon dispersion in water.

The high surface area and network structure of the KCNF greatly influences its capability to impregnate the temephos, a point consistent with studies by Zhao et al. (2015) and Plappert et al. (2019), whereby the high surface area 
Table 1. The mean amount of temephos impregnated on the powder KCNF+T (sample A), released in the water dispersed with 5 mg of the KCNF+T (sample B), retained in KCNF+T filtered from the water solution of sample B at the $1^{\text {st }}$ month (sample C), $3^{\text {rd }}$ month (sample $D$ ) and $5^{\text {th }}$ month (sample E) determined using HPLC

\begin{tabular}{|c|c|c|c|}
\hline Sample & Description of source & $\begin{array}{l}\text { Amount of temephos, mg } \\
\text { (Mean } \pm \text { SD) }\end{array}$ & $\begin{array}{c}\text { Temephos impregnated (IP)/ retention (RT)/ } \\
\text { release }(R L), \%(\text { Mean } \pm S D)\end{array}$ \\
\hline A & Powder KCNF+T (1.94 \%w/w temephos) & $0.097 \pm 0.007$ & IP in the $\mathrm{KCNF}+\mathrm{T}=97.0 \pm 7.0$ \\
\hline B & Water dispersed with sample $A^{*}$ & $0.051 \pm 0.003$ & $\mathrm{RL}$ into the water $=52.5 \pm 2.8$ \\
\hline C & Filtered from the sample $B-1^{\text {st }}$ month ${ }^{* *}$ & $0.029 \pm 0.002$ & $\mathrm{RT}$ in the $\mathrm{KCNF}+\mathrm{T}=29.8 \pm 1.9$ \\
\hline $\mathrm{D}$ & Filtered from the sample $B-3^{\text {rd }}$ month $^{* *}$ & $0.016 \pm 0.002$ & $\mathrm{RT}$ in the $\mathrm{KCNF}+\mathrm{T}=16.8 \pm 2.3$ \\
\hline$E$ & Filtered from the sample $B-5^{\text {th }}$ month $^{* *}$ & $0.007 \pm 0.001$ & $\mathrm{RT}$ in the $\mathrm{KCNF}+\mathrm{T}=6.8 \pm 0.9$ \\
\hline
\end{tabular}

* The $5 \mathrm{mg}$ of the sample A was dispersed into $100 \mathrm{ml}$ distilled water to achieve the intended amount of temephos equivalent to $1 \mathrm{mg} / \mathrm{L}$ (WHO, 2006).

** KCNF+T was collected by filtering the solution with the $0.1 \mu \mathrm{m}$ Omnipore PTFE membrane filter (MERCK KGaA, Germany).

nanocellulose was found to improve drug loading. It is suggested that the temephos could possibly interact with the KCNF through the formation of a weak intermolecular hydrogen bond between the $\mathrm{O}-\mathrm{CH} 3$ of the temephos and the $\mathrm{OH}$ group in the nanocellulose (NCBI 2020a, 2020b; Pietri \& Clark, 2020). The two aromatic rings composed of non-polar $\mathrm{C}-\mathrm{C}$ and $\mathrm{C}-\mathrm{H}$ bonds in the temephos molecules that caused the larvicide to exhibit hydrophobic properties (NCBI, 2020b). This study suggests that adsorption and precipitation were the main interactions between the KCNF and the temephos particles, reflecting the affinity of temephos to nanocellulose as described by Lombardo et al. (2018).

The amount of temephos released was $0.051 \mathrm{mg}$, indicating that approximately $53 \%$ of the temephos was released from the $\mathrm{KCNF}+\mathrm{T}$ upon dispersion in the distilled water. The swelling ability of nanocellulose in the presence of water and adsorption of temephos at the polymeric structure of KCNF may have enhanced its aqueous dispersibility due to the abundance of hydroxyl groups in the non-modified surface of the KCNF+T while releasing the temephos through the dissolution mechanism (Roy et al., 2014; De France et al., 2017). A possible explanation is the presence of water throughout the dispersion process, which may have led to the molecular mobility of the loaded larvicide (Rumondor et al., 2009). This is consistent with another study where a hydrophilic carrier was reported to cause swelling and the release of the drug in the presence of water (Bhandari et al., 2017).

On the other hand, the KCNF was found to be capable of retaining the temephos on its fibres at $30 \%$, but the percentage gradually decreased to $17 \%-7 \%$ during the five months after dispersion in the water (Table 1 ). This shows that the KCNF is able to prolong the retention of the temephos. The capability of carrier materials to retain active ingredients is essential so that pest control efficacy can be increased for an extended period and thus, the need to reapply larvicide is reduced (Nuruzzaman et al., 2016). Phuanukoonnon et al. (2006) reported that public ignorance in reapplying larvicide at regular intervals has led to failures in mosquito control programmes. When comparing KCNF+T with a commercial formulation of temephos (e.g. Abate ${ }^{\circledR} 1 S G$ ), the residual efficacy of the commercial product prepared at the same concentration $(1 \mathrm{mg} / \mathrm{L})$ was found to be at 15 to 26 weeks (Chen \& Lee, 2006; Lau et al., 2015). Hence, with the ability to retain temephos for up to five months, it is anticipated that the KCNF as a temephos carrier could extend the efficacy of the larvicide for longer periods. However, further residual efficacy studies should be carried out to ascertain the effect on mosquito larvae. It was postulated that the network and fibrous structure of the KCNF is the contributing factor that enhances the ability of the KCNF to retain the temephos upon dispersion in water. The network structure of the KCNF is envisaged to be able to retain the larvicide as it creates a tortuous diffusion path in the presence of water after dispersion, which translates into a prolonged retention of the temephos while indirectly being released (Lombardo et al., 2018).

\section{Larvicidal bioefficacy of KCNF+T against $\boldsymbol{A}$. aegypti larva}

The bioefficacy of all twelve test solutions against the A. aegypti larvae are shown in Figure 3. The A. aegypti larvae in the control solution (distilled water) showed mortality of less than $5 \%$, therefore Abbot's correction was not needed. The KCNF+T test solutions with the temephos concentration of 0.008 and $0.01 \mathrm{mg} / \mathrm{L}$ showed mean mortality above $90 \%$ at 24 and 48 hours of exposure, whereas the KCNF+T concentrations at $0.002,0.004$, and $0.006 \mathrm{mg} / \mathrm{L}$ caused less mean mortality of $5 \%, 21 \%$, and $68 \%$, respectively. For the larvae exposed to the TM test solutions, the mean mortality was below $5 \%$ for all five concentrations for both 24 and 48 hours. The non-parametric test of Kruskal-Wallis ANOVA showed a significant difference in mortality between KCNF+T and TM test solutions, $\chi 2(2)=319.3, p<0.05$. The Dunn's pairwise comparison with Bonferroni adjustments showed that lower concentration (below $0.004 \mathrm{mg} / \mathrm{L}$ ) of $\mathrm{KCNF}+\mathrm{T}$ exhibited significant differences in mortality compared with higher $\mathrm{KCNF}+\mathrm{T}$ test concentrations $(0.006$ to $0.01 \mathrm{mg} / \mathrm{L})$. Nevertheless, the percentage mortality was not a significant difference $(p>0.05)$ between KCNF+T test solutions of 0.006 $\mathrm{mg} / \mathrm{L}, 0.008 \mathrm{mg} / \mathrm{L}$, and $0.01 \mathrm{mg} / \mathrm{L}$.

The good bioefficacy shown by the current study is similar to the findings reported by Rahim et al. (2016), with mortality of Aedes mosquito larvae between $35 \%-78 \%$ mortality upon exposure to temephos diluted with ethanol as the carrier solvent at $0.004 \mathrm{mg} / \mathrm{L}$ to $0.005 \mathrm{mg} / \mathrm{L}$. Whilst the poor bioefficacy of the TM test solution is proven by the zero to low mortality of $A$. aegypti larvae upon exposure to temephos diluted in distilled water without organic solvent due to the poor water solubility of temephos (Rathburn, 1985; WHO, 2011). The efficacy comparison study between KCNF+T and TM at three test concentrations $(0.006,0.008$ and $0.01 \mathrm{mg} / \mathrm{L})$ suggested that the use of KCNF as a temephos carrier has notably increased the solution's bioefficacy against the $A$. aegypti larvae between 17 to 25 folds. Thus, this study showed that $\mathrm{KCNF}+\mathrm{T}$ is able to cause larval mortality without the presence of hazardous organic solvents.

Table 2 showed the Probit analysis of the larvicidal activity of $\mathrm{KCNF}+\mathrm{T}$ treatment solutions. The calculated $\mathrm{LC}_{50}$ for KCNF+T treatment solutions was $0.005 \mathrm{mg} / \mathrm{L}$ for 24 and 48 hours, while $L_{95}$ was 0.009 and $0.008 \mathrm{mg} / \mathrm{L}$ for 24 and 48 hours, respectively. Probit analysis for TM test solution was not carried out as the mortality percentage did not 


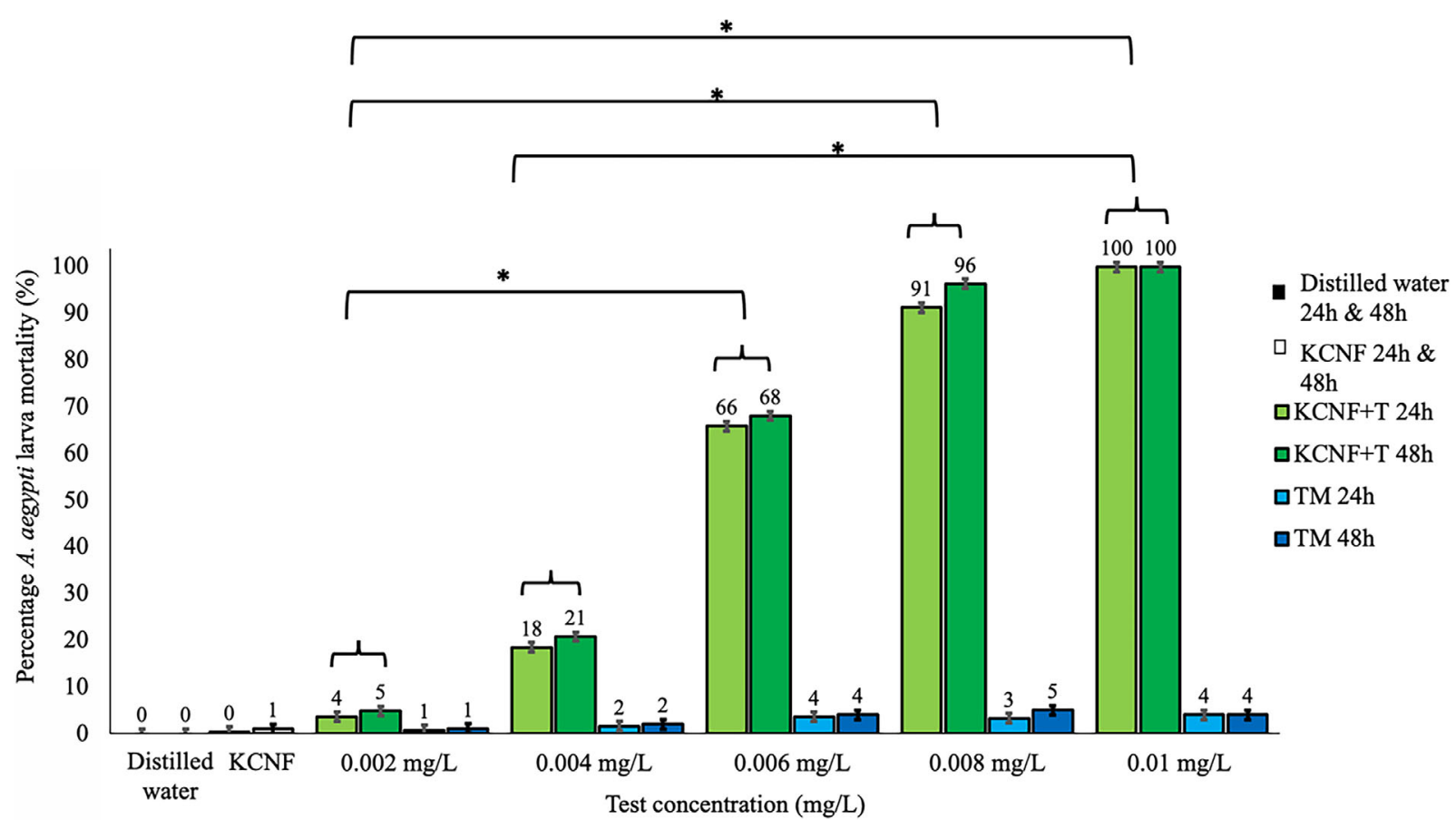

Figure 3. Percentage (\%) mortality at 24 and 48 hours of the A. aegypti larvae upon exposure with the treatment solutions of the distilled water (control), kenaf cellulose nanofibre (KCNF), temephos impregnated KCNF (KCNF+T) and temephos (TM) only at temephos concentration of $0.002,0.004,0.006,0.008$ and $0.01 \mathrm{mg} / \mathrm{L}$. Bars with asterisks $(*)$ indicate a significant difference between KCNF+T test concentrations by Dunn's mean comparison with Bonferroni adjustments, $p<0.05$.

Table 2. Probit dose-mortality analysis of $A$. aegypti larvae exposed to kenaf cellulose nanofibre impregnated with temephos (KCNF+T) and temephos only (TM) at the 24 and 48 hours

\begin{tabular}{|c|c|c|c|c|c|c|c|c|c|c|c|}
\hline \multirow{2}{*}{$\frac{\text { Test }}{\text { solution }}$} & \multirow[t]{2}{*}{$n$} & \multicolumn{5}{|c|}{$24 \mathrm{~h}$} & \multicolumn{5}{|c|}{$48 \mathrm{~h}$} \\
\hline & & $\begin{array}{c}\mathrm{LC}_{50} \\
(95 \% \mathrm{CL})\end{array}$ & $\begin{array}{c}\mathrm{LC}_{95} \\
(95 \% \mathrm{CL})\end{array}$ & $X^{2}(\mathrm{df})$ & $P$-values & $r^{2}$ & $\begin{array}{c}\mathrm{LC}_{50} \\
(95 \% \mathrm{CL})\end{array}$ & $\begin{array}{c}\mathrm{LC}_{95} \\
(95 \% \mathrm{CL})\end{array}$ & $x^{2}(\mathrm{df})$ & $P$-values & $r^{2}$ \\
\hline $\mathrm{KCNF}+\mathrm{T}$ & 2500 & $\begin{array}{c}0.005 \\
(0.005-0.006)\end{array}$ & $\begin{array}{c}0.009 \\
(0.007-0.012)\end{array}$ & $11.928(2)$ & 0.003 & 0.949 & $\begin{array}{c}0.005 \\
(0.005-0.006)\end{array}$ & $\begin{array}{c}0.008 \\
(0.007-0.010)\end{array}$ & $6.223(2)$ & 0.045 & 0.930 \\
\hline TM & 2500 & Not analyzed $b$ & ause the mor & lity did not & chieve 1 & 6 to 95 & & & & & \\
\hline
\end{tabular}

achieve the $10-95 \%$. The result suggests that KCNF has an influential role as a temephos carrier in controlling $A$. aegypti mosquito larvae. The $\mathrm{LC}_{50}$ of KCNF+T was found lower with the $\mathrm{LC}_{50}$ of the $A$ bate ${ }^{\circledR} 1 \mathrm{SG}$, a commercial temephos larvicide product at $0.00957 \mathrm{mg} / \mathrm{L}$ as reported by Aribudi et al. (2012). Based on the $\mathrm{LC}_{50}$ value, it is shown that KCNF as a larvicide carrier has the ability to enhance the larvicidal activity of the temephos even at low concentration $(0.005 \mathrm{mg} / \mathrm{L})$.

The microscopic examination of the larvae after 48 hours is shown in Figure 4. There was no notable morphological change on the larvae exposed in both test solutions. However, white matter was seen at the thorax, abdomen, and siphon of the larvae exposed in KCNF+T at $0.01 \mathrm{mg} / \mathrm{L}$. It is suggested to be the KCNF because the white matter was not observed for the larvae exposed to TM test solutions at the same concentration (Figure $4 b$ ).

The larvicidal activity confirmed the release of the temephos from KCNF, which caused the larvae mortality. The affinity of the KCNF+T to accumulate at the larvae appendages further increased the body surface contact of the larvae with temephos retained by the KCNFs, leading to enhance bioefficacy. It was postulated that the KCNF+T's ionic surface and $A$. aegypti larvae surface charge resulted in the dipoledipole interaction. The aggregation of the $\mathrm{KCNF}+\mathrm{T}$, which adhered firmly to the body surface of the insect can be seen by the attachment of KCNF+T at the larvae mouth, leg, and siphon, as indicated by the red arrows in Figure 4 (Howse \& Underwood, 2000; Stadler et al., 2017). This attachment is due to the triboelectrification generated by the insect's body surface attracted the nanofibres (McGonigle et al., 2002; Stadler et al., 2017). Triboelectrification is an electrostatic charging exchange between two surfaces when brought into contact (Schein et al., 2014). Attachment of the KCNF+T on the area surrounding the larvae body may result in transcuticular delivery and eventually, penetration of the temephos through other than gut delivery since there was no presence of KCNF in the digestive tract of the larvae (Howse \& Underwood, 2000; Phanse et al., 2015). The temephos was able to penetrate the epicuticular layer of the mosquito larvae through contact with the larvae's body surface, therefore affecting the larvae's nervous system due to its lipophilic property (Leesch \& Fukuto, 1972; Katagi \& Tanaka, 2016). 


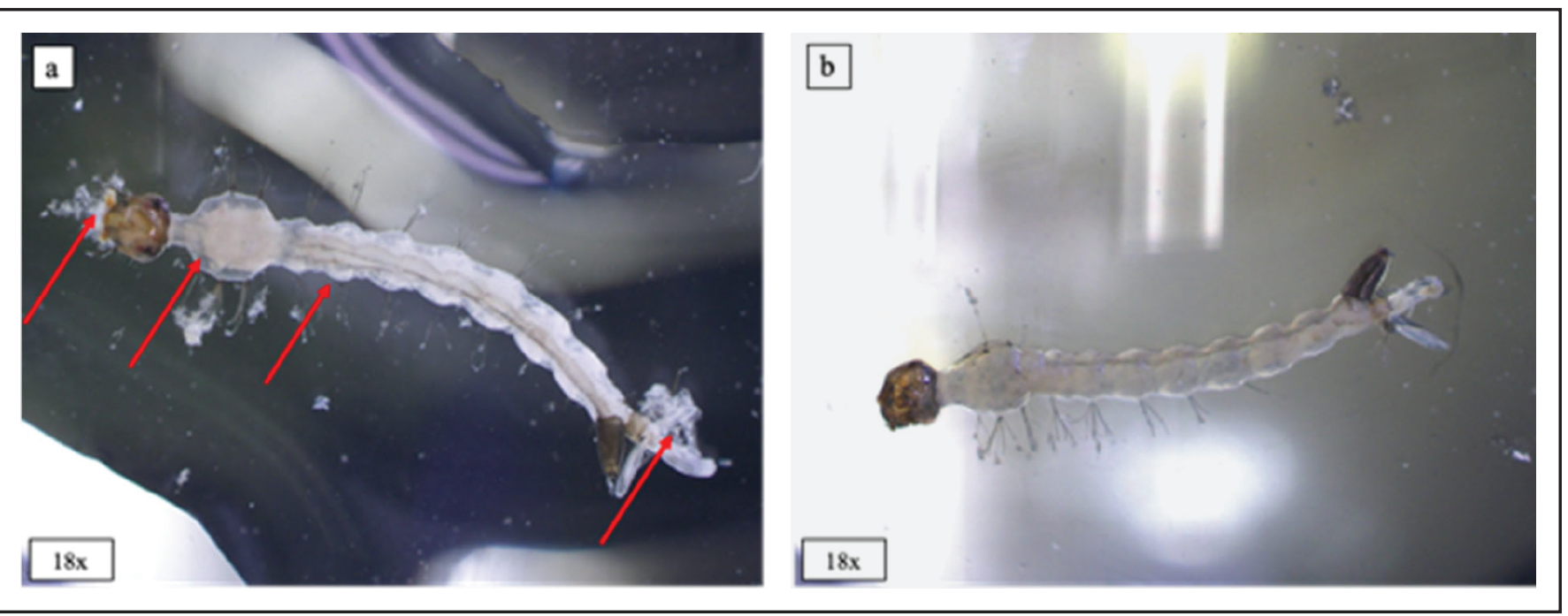

Figure 4. Specimen of $A$. aegypti larva on slide exposed to $0.01 \mathrm{mg} / \mathrm{L}$ temephos of the KCNF+T (a), and $0.01 \mathrm{mg} / \mathrm{L}$ of TM test solution (b) after 48 hours of exposure at 18x. Red arrows indicated KCNF+T at the thorax, abdomen, and siphon of the larva.

\section{CONCLUSION}

This study demonstrated the capability to impregnate temephos onto the surface of the KCNF up to $97 \%$ from $0.1 \mathrm{mg}$ temephos solution, producing KCNF+T with $1.94 \% \mathrm{w} / \mathrm{w}$. The study also showed that $53 \%$ of the impregnated temephos can be immediately released by the KCNF upon initial dispersion into the water. The KCNF+T also exhibited residual retention levels of $30 \%, 17 \%$ and $7 \%$ when left up to one, three and five months respectively. Furthermore, the KCNF+T effectively killed more than $60 \%$ of the $A$. aegypti larvae within 24 hours at the concentration of $0.006 \mathrm{mg} / \mathrm{L}$ to $0.01 \mathrm{mg} / \mathrm{L}$ temephos with 17 to 25 folds as compared to TM solutions without KCNF. The larval mortality was also enhanced by the accumulation of the KCNF+T on the larvae appendages. These results suggest the KNCF's potential as an effective carrier in delivering temephos for the control of $A$. aegypti mosquito larvae without the use of organic solvent.

\section{ACKNOWLEDGMENTS}

The authors would like to acknowledge Hextar R\&D International Sdn. Bhd. for the supply of temephos and technical assistance for HPLC analysis, Dr. Rahmatullah Holding Sdn. Bhd. for the supply of raw kenaf bast, Vector Control Research Unit (VCRU) Universiti Sains Malaysia (USM) for the supply of larvae and Animal Research Section and Integrative Medicine Cluster, USM for the laboratory facilities. This work was supported by USM KPI/MyRA grant (1001:CIPPT.AUPS001) and UIAA Intellectual Advisory funding [ORO/20/11-UIAA(1)]. Appreciation was also given to the Ministry of Higher Learning, Malaysia, and Universiti Malaysia Perlis (UniMAP) for the doctorate study scholarship.

\section{Conflict of interest}

The authors declare that they have no conflicts of interest.

\section{REFERENCES}

Abdul Khalil, H.P.S., Yusra, A.F.I., Bhat, A.H. \& Jawaid, M. (2010). Cell wall ultrastructure, anatomy, lignin distribution, and chemical composition of Malaysian cultivated kenaf fibre. Industrial Crops Production 31: 113-121. https://doi.org/ 10.1016/j.indcrop.2009.09.008
Aribudi, I., Heriyani, F. \& Isnaini. (2012). Resistance status of Aedes aegypti larvae to temephos in West Banjarmasin. Jurnal Epidemiologi dan Penyakit Bersumber Binatang 4: 5358.

Badawy, M.E.I., Taktak, N.E.M., Awad, O.M., Elfiki, A. \& El-ela, N.E.A. (2015). Larvicidal activity of temephos released from new chitosan/alginate/gelatin capsules against Culex pipiens. International Journal of Mosquito Research 2: 45-55.

Basri, M.H.A, Abdu, A., Junejo, N., Hamid, H.A. \& Ahmed, K. (2014). Journey of kenaf in Malaysia: A review. Scientific Research and Essays 9: 458-470. https://doi.org/10.5897/ SRE12.471

Bhandari, J., Mishra, H., Mishra, P.K., Wimmer, R., Ahmad, F.J. \& Talegaonkar, S. (2017). Cellulose nanofibre aerogel as a promising biomaterial for customized oral drug delivery. International Journal of Nanomedicine 12: 2021-2031. https:/ /doi.org/10.2147/IJN.S124318

Chen, C.D. \& Lee, H.L. (2006) Laboratory bioefficacy of CREEK 1.0G (temephos) against Aedes (Stegomyia) aegypti (Linnaeus) larvae. Tropical Biomedicine 23: 220-223.

Collaborative International Pesticides Analytical Council [CIPAC] (1985). CIPAC Handbook 1C. Temephos (340). Harpenden, United Kingdom, pp. 2230.

De France, K.J., Hoare, T. \& Cranston, E.D. (2017). Review of hydrogels and aerogels containing nanocellulose. Chemistry of Materials 29: 4609-4631. https://doi.org/ 10.1021/acs.chemmater.7b00531

Finney, D.J. (1971). Probit Analysis. Cambridge University Press. Cambridge, United Kingdom.

Floore, T.G. (2006). Mosquito larval control practices: past and present. Journal of the American Mosquito Control Association 22: 527-533. https://doi.org/10.2987/8756971X(2006)22[527:MLCPPA]2.0.CO;2

French, A.D. (2017). Glucose, not cellobiose, is the repeating unit of cellulose and why that is important. Cellulose 24: 4605-4609. https://doi.org/10.1007/s10570-017-1450-3

Henry, R.A., Schmit, J.A., Dieckman, J.F. \& Murphey, F.J. (1971). Combined high speed liquid chromatography and bioassay for the evaluation and analysis of an organophosphorus larvicide. Analytical Chemistry 43: 1053-1057. https://doi.org/10.1021/ac60303a019

Howse, P.E. \& Underwood, K.L. (2000). Environmentally safe pest control using novel bioelectrostatic techniques: Initial results and prospects for area-wide usage. In: 
Area-Wide Control of Fruit Flies and Other Insect Pests, Tan, K.H. (editor). Pulau Pinang: Penerbit Universiti Sains Malaysia, pp. 295-299.

IBM Corp (2020). IBM SPSS Statistics for Macintosh. Armonk, NY: IBM Corp.

Jansen, C.C. \& Beebe, N.W. (2010). The dengue vector Aedes aegypti: what comes next. Microbes and Infection 12: 272279. https://doi.org/10.1016/j.micinf.2009.12.011

Kadam, S.L., Yadav, P., Bhutkar, S., Patil, V.D., Shukla, P.G. \& Shanmuganathan, K. (2019). Sustained release insect repellent microcapsules using modified cellulose nanofibres (mCNF) as pickering emulsifier. Colloids and Surfaces A: Physicochemical and Engineering Aspects 582: 123883. https://doi.org/10.1016/j.colsurfa.2019.123883

Kase, L.E. \& Branton, P.L. (1986). Floating article for improved control of aquatic insects. United States patent application US4631857A.

Katagi, T. \& Tanaka, H. (2016). Metabolism, bioaccumulation, and toxicity of pesticides in aquatic insect larvae. Journal of Pesticide Science 41: 25-37. https://doi.org/10.1584/ jpestics.D15-064

Laerd Statistics (2017). Statistical tutorials and software guides. https://statistics.laerd.com/. Accessed 17 October 2020.

Lau, K.W., Chen, C.D., Lee, H.L. \& Sofian-Azirun, M. (2015). Evaluation of insect growth regulators, temephos and Bacillus thuringiensis israelensis against Aedes aegypti $(\mathrm{L})$ in plastic containers. Tropical Biomedicine 32: 684-692.

Leesch, J.G. \& Fukuto, T.R. (1972). The metabolism of abate in mosquito larvae and houseflies. Pesticide Biochemistry and Physiology 2: 223-235. https://doi.org/10.1016/00483575(72)90025-9

Lombardo, S., Chen, P., Larsson, P.A., Thielemans, W., Wohlert, J. \& Svagan, A.J. (2018). Towards improved understanding of the interactions between poorly soluble drugs and cellulose nanofibres. Langmuir 34: 5464-5473. https://doi. org/10.1021/acs.langmuir.8b00531

McGonigle, D.F., Jackson, C.W. \& Davidson, J.L. (2002). Triboelectrification of houseflies (Musca domestica L.) walking on synthetic dielectric surfaces. Journal of Electrostatics 54: 167-177. https://doi.org/10.1016/S03043886(01)00177-2

National Center for Biotechnology Information (NCBI) (2020a) PubChem Compound Summary for CID 16211032, Cellulose. https://pubchem.ncbi.nlm.nih.gov/compound/Deaecellulose. Accessed 28 November 2020.

National Center for Biotechnology Information (NCBI) (2020b). PubChem Compound Summary for CID 5392, Temephos. https://pubchem.ncbi.nlm.nih.gov/compound/Temephos. Accessed 28 November 2020.

National Pesticide Information Center (NPIC) (2011). Insert or "other" ingredients. http://npic.orst.edu/factsheets/ inerts.html. Accessed 18 September 2020.

Nechyporchuk, O., Belgacem, M.N. \& Bras, J. (2016). Production of cellulose nanofibrils: A review of recent advances. Industrial Crops and Products 93: 2-25. https://doi.org/10.1016/ j.indcrop.2016.02.016

Nuruzzaman, M., Rahman, M.M., Liu, Y. \& Naidu, R. (2016) Nanoencapsulation, nano-guard for pesticides: A new window for safe application. Journal of Agricultural and Food Chemistry 64: 1447-1483. https://doi.org/10.1021/ acs.jafc.5b05214

Ong, K.J., Shatkin, J.A., Nelson, K., Ede, J.D. \& Retsina, T. (2017). Establishing the safety of novel bio-based cellulose nanomaterials for commercialization. Nanolmpact 6: 1929. https://doi.org/10.1016/j.impact.2017.03.002
Organisation for Economic Cooperation and Development (OECD) (2017). Test No. 318: Dispersion stability of nanomaterials in simulated environmental media. OECD guidelines for the testing of chemicals. Section 3. Paris: OECD Publishing.

Pengiran, H., Kamaldin, J., Fen, L.B. \& Yusob, S.A.A. (2021). Properties of kenaf cellulose nanofiber (CNF) as potential larvicide nanocarrier and its acute ecotoxicity against Daphnia magna and Dania rerio. Journal of Natural Fibres. https://doi.org/10.1080/15440478.2021.1932673

Phanse, Y., Dunphy, B.M., Perry, J.L., Airs, P.M., Paquette, C.C.H., Carlson, J.O., Xu, J., Luft, J.C., DeSimone, J.M., Beaty, B.J. et al. (2015). Biodistribution and toxicity studies of PRINT hydrogel nanoparticles in mosquito larvae and cells. PLOS Neglected Tropical Diseases 9: e0003735. https://doi.org/ 10.1371/journal.pntd.0003735

Phuanukoonnon, S., Bough, M. \& Bryan, J.H. (2006). Household practices of temephos use for dengue larval control, Khon Kaen province, north-east Thailand. Dengue Bulletin 30: 251-259.

Pietri, J. \& Clark, J. (2020). Hydrogen bonding. https://chem. libretexts.org/Bookshelves/Physical_and_Theoretical_ Chemistry_Textbook_Maps/Supplemental_Modules_ (Physical_and_Theoretical_Chemistry)/Physical_ Properties_of_Matter/Atomic_and_Molecular_ Properties/Intermolecular_Forces/Specific_Interactions/ Hydrogen_Bonding. Accessed 29 November 2020.

Plappert, S.F., Liebner, F.W., Konnerth, J. \& Nedelec, J.M. (2019). Anisotropic nanocellulose gel - membranes for drug delivery: Tailoring structure and interface by sequential periodate-chlorite oxidation. Carbohydrate Polymer 226: 115306. https://doi.org/10.1016/j.carbpol.2019.115306

Pötzinger, Y., Kralisch, D. \& Fischer, D. (2017). Bacterial nanocellulose: The future of controlled drug delivery? Therapeutic Delivery 8: 753-761. https://doi.org/10.4155/tde2017-0059

Rasmussen, K., Rauscher, H., Mech, A., Sintes, J.R., Gilliland, D., González, M., Kearns, P., Moss, K., Visser, M., Groenewold, M. et al. (2018). Physico-chemical properties of manufactured nanomaterials-characterisation and relevant methods. An outlook based on the OECD Testing Programme. Regulatory Toxicology and Pharmacology 92: 8-28. https://doi.org/10.1016/j.yrtph.2017.10.019

Rahim, J., Ahmad, A.H., Kassim, N.F., Ahmad, H., Ishak, I.H., Rus, A.C. \& Maimusa, H.A. (2016). Revised discriminating lethal doses for resistance monitoring program on Aedes albopictus against temephos and malathion in Penang Island, Malaysia. Journal of the American Mosquito Control Association 32: 210-216. https://doi.org/10.2987/16-6556.1

Rathburn, C.B. (1985). Insecticide formulations-types and uses: A review. Journal of the American Mosquito Control Association 1: 80-84.

Rios, L.M., Moore, C. \& Jones, P.R. (2007). Persistent organic pollutants carried by synthetic polymers in the ocean environment. Marine Pollution Bulletin 54: 1230-1237. https://doi.org/10.1016/j.marpolbul.2007.03.022

Roy, A., Singh, S.K., Bajpai, J. \& Bajpai, A.K. (2014). Controlled pesticide release from biodegradable polymers. Central European Journal of Chemistry 12: 453-469. https://doi.org/ 10.2478/s11532-013-0405-2

Rumondor, A.C.F., Marsac, P.J., Stanford, L.A. \& Taylor, L.S. (2009). Phase behavior of poly(vinylpyrrolidone) containing amorphous solid dispersions in the presence of moisture. Molecular Pharmaceutics 6: 1492-1505. https:// doi.org/10.1021/mp900050c 
Schein, L.B., Castle, G.S.P. \& Lacks, D.J. (2014). Triboelectrification. In: Wiley Encyclopedia of Electrical and Electronics Engineering, Webster, J.G. (editor). John Wiley \& Sons, Inc, pp. 1-14.

Schneider, C.A., Rasband, W.S. \& Eliceiri, K.W. (2012). NIH Image to ImageJ: 25 years of image analysis. Nature Methods 9: 671-675. https://doi.org/10.1038/nmeth.2089

Schorkopf, D.L.P., Spanoudis, C.G., Mboera, L.E.G., Mafra-Neto, A., Ignell, R. \& Dekker, T. (2016). Combining attractants and larvicides in biodegradable matrices for sustainable mosquito vector control. PLoS Neglected Tropical Diseases 10: e0005043. https://doi.org/10.1371/journal.pntd.0005043

Stadler, T., López García, G.P., Gitto, J.G. \& Buteler, M. (2017). Nanostructured alumina: Biocidal properties and mechanism of action of a novel insecticide powder. Bulletin of Insectology 70: 17-25.

Tuerxun, D., Pulingam, T., Nordin, N.I., Chen, Y.W., Kamaldin, J., Julkapli, N.B.M., Lee, H.V., Leo, B.F. \& Johan, M.R.B. (2019). Synthesis, characterization and cytotoxicity studies of nanocrystalline cellulose from the production waste of rubber-wood and kenaf-bast fibers. European Polymer Journal 116: 352-360. https://doi.org/10.1016/j.eurpolymj. 2019.04.021

United Nations (UN) (2015). Sustainable development goals. https://sdgs.un.org/goals/goal3. Accessed 20 January 2021.

US Environmental Protection Agency (US EPA) (2019). Basic information about pesticide ingredients | Ingredients used in pesticide products. https://www.epa.gov/ ingredients-used-pesticide-products/basic-informationabout-pesticide-ingredients. Accessed 18 September 2020.
US Environmental Protection Agency (US EPA) (2019). Success in mosquito control: an integrated approach. https:// www.epa.gov/mosquitocontrol/success-mosquitocontrol-integrated-approach. Accessed 24 August 2020.

World Health Organisation (WHO) (2004). Global strategic framework for Integrated Vector Management. http:// apps.who.int/iris/bitstream/handle/10665/68624/ WHO_CDS_CPE_PVC_2004_10.pdf?sequence $=1$. Accessed 24 August 2020.

World Health Organisation (WHO) (2005). Guidelines for laboratory and field testing of mosquito larvicides. WHO. Geneva.

World Health Organisation (WHO) (2006). Pesticides their application for the control of vectors and pests of public health importance. WHO. Geneva.

World Health Organisation (WHO) (2011). WHO specification and evaluations for public health pesticides: Temephos. WHO. Geneva.

World Health Organisation (WHO) (2020). Dengue and severe dengue. WHO Fact Sheet. https://www.who.int/en/news$\mathrm{room} /$ fact-sheets/detail/dengue-and-severe-dengue. Accessed 23 August 2020.

Yusoff, S.N.M., Kamari, A. \& Aljafree, N.F.A. (2016). A review of materials used as carrier agents in pesticide formulations. International Journal of Environmental Science and Technology 13: 2977-2994. https://doi.org/10.1007/s13762016-1096-y

Zhao, J., Lu, C., He, X., Zhang, X., Zhang, W. \& Zhang, X. (2015). Polyethylenimine-grafted cellulose nanofibril aerogels as versatile vehicles for drug delivery. ACS Applied Materials \& Interfaces 7: 2607-2615. https://doi.org/10.1021/am $507601 \mathrm{~m}$ 